\title{
DICE JOSÉ ANTONIO GÓMEZ, CÉLEBRE PROFESOR DE FORTE-PIANO: “¿Y ES ESTO TODO LO QUE HAY QUE TOCAR DE MÁS DIFÍCIL?”
}

\author{
THE CELEBRATED FORTE-PIANO TEACHER, \\ JOSE ANTONIO GOMEZ, SAID: \\ “AND YOU DON'T HAVE ANYTHING MORE DIFFICULT TO PLAY?”
}

\section{Resumen:}

Tomando como punto de partida el siglo XVI, se puede decir que México cuenta con una vasta y rica tradición musical. Empero, poco se conoce de los músicos y la música del periodo del México Independiente, el siglo XIX. Por ejemplo, a pesar de que es normal encontrar el nombre de José Antonio Gómez en la literatura musical de este periodo, dicha información tiende a ser repetida y limitada. Este ensayo revisa parte de esta literatura para proceder así a cotejarla con fuentes de primera mano provenientes de la Catedral Metropolitana de la Ciudad de México como de sus propias publicaciones. En síntesis, además de demostrar la importancia como músico prolífico en los ámbitos religioso y secular, la intención del autor es presentar a Gómez como figura clave para acercarse y entender el periodo de la música que menos estudios ha recibido, periodo que coincide con los orígenes de México como nación.

Palabras claves:

México Independiente, Catedral Metropolitana, Ópera italiana, Métodos musicales, José Antonio Gómez.

\begin{abstract}
:
Taking the sixteenth century as a point of departure, it can be said that Mexico has a vast and rich music tradition. However, not much is known about the musicians and the music from Independent Mexico, the nineteenth century. The name of José Antonio Gómez, for instance, appears in much of the music literature from and about this period, wherein the limited information presented tends to repeat itself. This essay examines Gómez in light of the existing literature and in relation to original documents from the Mexico City Cathedral and his own publications. Apart from showing his importance as one of the most prolific musicians of both the religious and secular milieus, it is the intention of this author to demonstrate how Gómez is a key figure to approach and understand the music period that has received least studies, a period that coincides with the origins of Mexico as a nation.
\end{abstract}

Key words:

Independent Mexico, Mexico City Cathedral, Italian Opera, Music Methods, José Antonio Gómez. 
Si en todas épocas y en todos los países ha producido la naturaleza varones insignes que han sobresalido, ya en las ciencias, ya en las artes, no se ha manifestado menos pródiga en Mégico, donde han lucido por sus talentos hombres dedicados á toda clase de profesiones científicas y liberales. Entre estos debe contarse el célebre profesor de forte-piano don José Antonio Gómez, ornamento de su patria, que ha brillado como la luna llena en el cielo, y á quien por su rara habilidad en el arte de la música dedicamos esta breve BIOGRAFÍA. ${ }^{1}$

\section{INTRODUCCIÓN}

La práctica de la música en México ha legado una abundancia invaluable de géneros y estilos, y para sorpresa de muchos, algunos de ellos siguen a la espera de su estudio. Tomando como referencia el siglo XVI, la práctica musical jugó un papel esencial en el establecimiento de la Iglesia Católica en la Nueva España — período que comprendería hasta el XVIII—. Desde entonces, y hasta finales del siglo XIX, la liturgia tendría en la música a una de sus actividades principales. Empero, encontramos precisamente en este último siglo de actividades musicales que los filarmónicos de entonces, como de sus obras, han permanecido ausentes tanto de los estudios musicales y — que es lo más fundamental— de los escenarios de concierto. Por estas razones, el presente ensayo toma como punto de partida a uno de los personajes principales del quehacer musical del México Independiente.

El Calendario Filarmónico para 1866. Arreglado al Meridiano de México (véase abajo), resume de manera coloquial detalles tomados de dos episodios encontrados en la vida de José Antonio Gómez y Olguín (1805-1876). ${ }^{2}$ El primero ocurrió en 1835 cuando el anónimo autor recuerda cómo el joven Gómez sorprendiera a los "severos sinodales" quienes sin discusión lo hicieron merecedor del privilegiado puesto de primer organista de la Catedral Metropolitana. El segundo episodio cierra varios años después, en 1865, para cuando Gómez había pasado cuatro décadas de servir — hubo de ingresar en 1820 — en la Iglesia más importante del país; en este entonces, un maduro y decidido primer organista decide sin tapujos renunciar para "huir de la miseria" ocasionada por la "desamortización de bienes eclesiásticos". Mejor dejemos que nos acerque la nota completa del Calendario Filarmónico a nuestro personaje:

Sr. D. Antonio Gómez Olguín. Cuando era aún muy niño, optó la plaza de segundo organista de la Santa Iglesia Catedral de México; existen en el archivo de dicha iglesia muchas composiciones de órgano obligado, de las cuales se escogió lo más difícil para el examen del pretendiente; llegada la hora a nuestro joven de manifestar su saber y ejecución para la aprobación o desaprobación de los severos sinodales, con la mayor serenidad y aplomo tocó con una precisión y claridad aquellas dificultades estudiadas por el autor, que dejó sorprendidos a los señores capitulares presentes y a los severos sinodales; concluido esto, nuestro joven con una sencillez casi infantil, preguntó a

1 GALVÁN impr., 1840: 195-196.

2 Sobre el fallecimiento de José Antonio Gómez, véase el Registro Civil Tulancingo, Hidalgo, Actas de Defunciones, Proyecto GFC-206 (33839) 52 a , año de 1876. Del Fondo documental de genealogía del Archivo General de la Nación (en adelante, AGN), perteneciente a la Academia Mexicana de Genealogía. 
los que tenían en sus manos su suerte, ¿`y es esto todo lo que hay que tocar de más difícil?’ Esta pregunta candorosa produjo en los circunstantes un efecto tal, que se proveyó la plaza en su favor inmediatamente. Es célebre como pianista, profundo como compositor, pero en lo que arroba y encanta es en la improvisación en el órgano. ¡Ah! ¡Cuántas veces nosotros que le oímos tanto en la salmodia de las grandes festividades de la Asunción, San Pedro, Nuestra Señora de Guadalupe y San Felipe de Jesús en la Catedral, nos parecían las horas minutos para escucharle! ¡Gómez! ¡sólo Dios puede inspirarte lo que haces en el órgano! A consecuencia de la desamortización de bienes eclesiásticos, rebajaron el sueldo a todos los que dependían de la Catedral de una manera que asombra, pues a quien tenía, por ejemplo, sesenta pesos, lo redujeron a quince o diez, etc. Esto obligó al Sr. Gómez a solicitar la maestría de Capilla y plaza de organista de la nueva catedral de Tulancingo, donde actualmente se halla, para huir en lo posible de la miseria.

\section{S/A, artículo sobre José Antonio Gómez publicado en 1865. ${ }^{3}$}

Estas dos instancias dejan entrever por un lado su calidad como músico; sin embargo, lo cierto es que la literatura de la música mexicana ha dedicado escasas páginas a su prolífica labor. ${ }^{4}$ Dicho esto, examinaremos aquí parte del legado musical de Gómez poniendo en evidencia su papel protagónico durante un periodo complejo en la historia mexicana. Un breve resumen de lo que se ha escrito en la literatura de la música en México, tanto por mexicanos como por extranjeros, nos ilustra al cotejarlas con fuentes de primera mano tomadas de la Catedral Metropolitana como de sus propias publicaciones. De esta manera, la intensión es despertar el interés en quien es quizá una de las figuras claves para acercarse y entender la música durante las primeras décadas del México Independiente, por cierto, el periodo que menor atención ha recibido.

En este sentido parecería atrevido afirmar que estudios musicológicos en México han tomado con desdén al siglo XIX. ${ }^{5}$ Esto se sigue ya que el periodo en cuestión ha permanecido al margen de la prolífica Nueva España (siglos XVI al XVIII), que por su relación con España y la Iglesia Católica ha sido merecedora de amplias investigaciones, y del México moderno (siglo XX al presente), que por su asociación con el nacionalismo ha sido objeto ya de numerosos estudios. ${ }^{6}$ Esto no es ninguna novedad, ya que no hace mucho que Ricardo Miranda levantaba la voz para preguntar si entre fines del XVIII y

3 Véase S/A, (México, 1865): 56-58.

4 Sin ser una lista exhaustiva, referencias sobre Gómez se hayan en: SOSA, 1884: 414-417. GALINDO, 1933: $504-506$. ROMERO, 1934: 141-146. BAQUEIRO FOSTER, 1964: 121-122. ORTA VELÁZQUEZ, 1971: 268-270. GRIAL, $1973: 11-12$. MONCADA GARCÍA, 1979: 109-111. FLORES, 1986: 134-135. SALDÍVAR, 1991: 143-144. GUERBEROF HAHN, 2006: 15; PAREYÓN, 2007: 435-437.

5 Carlos Chávez $(* 1899 ; \nmid 1978)$ estaba tan convencido de la "etapa formativa primaria" que los "compositores del XIX tienen que haberse percatado de esto, más bien subconscientemente. Al principio, sin embargo, muy al principio, con una mentalidad digamos ingenua, han de haber estado felices de hacer una ópera lo más parecida posible a su modelo italiano.” CHÁVEZ, 1949: 30

6 Las figuras ideológicas del nacionalismo mexicano además de Chávez, son Manuel M. Ponce $(* 1886 ; \dagger 1948)$ y José Silvestre Revueltas $(* 1899 ; \nmid 1940)$. Empero, agudas son las palabras de Pulido hacia el discurso parcial formado alrededor de esta ideología: "Si partimos del hecho incontrovertible de que la música del pretendido periodo nacionalista no se conoce sino parcialmente, muy parcialmente [...] No caigamos en la trampa. Al abordar el estudio del nacionalismo musical mexicano, una elemental precaución de historiador — o analista — debe tenerse en consideración: distinguir explícitamente entre el discurso y la practica." PULIDO. ESCORZA, 8/2 (Texas, 1987): 285. 
principios del XIX había “....escapado a los ojos de intérpretes y musicólogos, o las fuentes han desaparecido con el tiempo...". De esto se ocupan las siguientes páginas, en responder a estas fundamentales cuestiones.

\section{UN FILARMÓNICO DEL MÉXICO INDEPENDIENTE}

Fue su oficio de filarmónico lo que llevó a Gómez a recorrer gran parte del siglo XIX. Pocos recuerdos habrá tenido del periodo de la Nueva España, pero sí del optimismo que se respiraba a principios del México Independiente, de las constantes luchas libradas entre gobiernos liberales y conservadores, de las ominosas invasiones militares, de la dolorosa perdida de la mitad del territorio, del complicado conflicto entre el Estado y la Iglesia hasta la promulgación de las Leyes de Reforma (1857), y todavía habría de vivir unos años más. Gómez falleció a la edad de 71 años.

Documentos del Archivo del Cabildo Catedral Metropolitano de México $(\boldsymbol{M E X}-\mathbf{M c}),{ }^{8}$ confirman su estancia en la Iglesia más importante entre 1820 y 1865..$^{9}$ Ahí sirvió, durante 30 años, como primer organista de la Catedral Metropolitana, espacio litúrgico que había acumulado para entonces tres siglos de monumental tradición musical. Desde aquí, y en medio de un ambiente volátil del que se caracterizó el siglo XIX, Gómez logró forjarse una reputable trayectoria musical que además de la Iglesia, incluyó a la sociedad mexicana de la capital independiente.

Una lectura escrupulosa de las referencias literarias sobre la música mexicana del siglo XIX (véase nota 4), evidencian lo insuficiente que ha sido el estudio de sus contribuciones en la Iglesia, comenzando por sus numerosos manuscritos religiosos, ${ }^{10}$ como de los varios métodos musicales que publicó y de los cuales son apenas conocidos por sus títulos. ${ }^{11}$ Hay que decir que el contenido en esta literatura, que abarca desde 1884 hasta prácticamente nuestros días se ha distinguido por repetir sus datos y por ende dejan entrever a un Gómez parco e insípido. Caso atípico, si se toma en cuenta de que a Gómez lo caracteriza su intensa actividad y ecléctica producción musical, prototipo del filarmónico decimonónico. Pasemos a revisar algunos fragmentos de lo que se ha escrito en dicha literatura.

7 MIRANDA, 116-117 (México, 1997): 39.

8 Antes como Biblioteca Turriana de la Catedral Metropolitana, gracias al padre Cayetano Torres, quien fundó en 1778 la primera biblioteca de la Nueva España.

9 La primera mención Gómez en la Catedral Metropolitana lo menciona como su tercer organista a solo unos meses de que México alcanzara su independencia, véase HERNÁNDEZ, 2011: 20.

10 Más de 80 en la Catedral Metropolitana, 11 en la Basílica de Guadalupe, cuatro en Guadalajara, 27 en Tulancingo y 2 en Chiapas. Los catálogos musicales de estas dos catedrales, Tulancingo y Chiapas, están para su consulta en la base de datos de Répertoire International des Sources Musicales (RISM).

11 Es la biografía de Francisco Sosa (véase nota 4) la que ha dado la pauta a la literatura sobre la música del siglo XIX, que con poca fortuna se ha dedicado a cotejar su contenido. 


\section{El maestro de maestros entre los mexicanos ${ }^{12}$}

Gómez nació en la Ciudad de México el 21 de abril de $1805 .{ }^{13}$ Su padre, José Santos Gómez, ${ }^{14}$ sabiendo del talento de su hijo decidió ofrecerle sus primeras lecciones musicales. Fue distinguido estudiante de la Colegiata de Guadalupe, apodado por su excepcional voz como el niño Gómez, ${ }^{15}$ donde era costumbre escucharlo cantar durante las misas solemnes en varias de las iglesias de la Ciudad de México como de su Catedral. Se dice que sus primeras obras las escribió a la edad de diez años. Entre sus profesores se encuentran Manuel Izquierdo, ${ }^{16}$ Magín Ginesta, ${ }^{17}$ y Manuel Corral $(* 1780 ; \dagger 1830) .{ }^{18}$

Cuentan que para 1827, dejó sorprendidos a los presentes cuando tocó medio-tono arriba (de Donatural a Do-sostenido) y a primera vista en el piano El amante astuto del afamado tenor español Manuel García (*1775; †1832). ${ }^{19}$ Su "fecundidad y su facilidad" eran tales, que escribía obras completas sin tener que corregir; cabe mencionar que entre sus títulos se mencionan La Historia de la Independencia, ${ }^{20}$ Miserere a ocho voces y su Te Deum. ${ }^{21}$ En 1839, anunció en pomposo evento que se llevó a cabo en el Palacio de Minería, la fundación de su Gran Sociedad Filarmónica para apoyar las actividades de su Conservatorio de Música (de ello regresaremos más abajo). Son precisamente entre estos años, hacia fines de 1830 y principios de 1840, en los que Gómez publica la gran mayoría de sus títulos musicales.

Mucho se ha escrito de que ocupó la plaza de maestro de capilla de la Catedral Metropolitana, ${ }^{22}$ posición que dada su calidad debió de haber ejercido, pero entonces la capilla musical ya había perdido el

12 Se debe a Melesio Morales $(* 1838 ; \dagger 1908)$, aunque su procedencia es incierta, esta frase con la que abre Francisco Sosa su biografía sobre Gómez.

13 Salvador Valdéz, fue hasta su fallecimiento en el 2011, el encargado del $\boldsymbol{M E X}$-Mc. Agradezco a Valdéz el haber encontrado la dirección de la familia Gómez: "Don José Santos Gómez, Doña Antonio Olguín y el niño José Antonio Gómez y Olguín, quienes vivían en la cuadra 15, en la Calle Puente de la Quebrada", hoy República del Salvador esquina con Eje Central. Véase MEX-Mc, Padrón de la Parroquia del Sagrario de esta Santa Iglesia Metropolitana de México...Año de 1816, Folio 39.

14 Probablemente organista de oficio, véase ORTA, 1971: 268.

15 El coro y la orquesta de la Colegiata de Guadalupe participaban regularmente en eventos religiosos. Gómez no solamente estudio aquí, pero también escribió y dirigió obras que dedicó a la Basílica. PAREYÓN, 2007: 251.

16 Manuel Izquierdo fue discípulo de Tollis de la Rocca, véase LEHMANN, 3 (México, 2008): 23.

17 Ginesta fue durante varios años organista y compositor de la Colegiata de Guadalupe, véase GUERBEROF HAHN, 2/33 (México, 2003): 9.

18 Compositor y director de orquesta de teatro español, Corral escribió para el pianoforte en 1811 — justo arrancando el periodo del movimiento independiente- Prisión de Hidalgo, Allende y demás insurgents, por las tropes del rey. También de su autoría, están las obras Los patriotas distinguidos de México, y poco antes de su partida de México, en 1821, dedicó a Iturbide su marcha titulada A las armas. Véase PAREYÓN, 2007: 284.

19 Manuel García es conocido por haber estrenado el papel de Almaviva en Il barbiere di Siviglia (1816) de Rossini. A pesar de las complicaciones que él y su familia vivieron durante su estancia, García tuvo gran éxito en los teatros mexicanos. Véase RADOMSKI, 2000: 211-243.

20 Sosa especifica la dotación para "piano, flauta, violin ó violoncello; obra del género imitativo", aunque también titulada como Pieza Histórica Sobre la Independencia de la Nación Mexicana (1823c), y La Gran Pieza Histórica de los últimos gloriosos sucesos de la Guerra de Independencia (1844). SOSA, 1884: 416.

21 “....el Tedéum estrenado en la función religiosa con la cual fue recibido Santa-Anna en la Catedral el domingo 21 de junio de 1835." ROMERO, 1961: 86. Por otro lado, en el $\boldsymbol{M E X}$ - $\boldsymbol{M c}$ la entrada de esta obra dice: "Partitura Original/ del Te Deum Laudamus/ a 4 voces. 2 Violines, 2 Violas,/ oboé, 2 Flautas, 2 Clarinetes/ 2 trompas, Fagot, Timbales,/ Organo obligado, Bajo/ organo y Bajo/ continuo/ Compuesto por/ J. Ant.o Gómez/ En Mej.co Año de 1835." Véase MEX-Mc , E10.24/ C2/ LEGBd3/ AM0810 E13.14/ C2/ LEGDd14/ AM1215.

22 Luis Baca, quien se dijo ser alumno de Gómez, publica en París su Ave Maria, donde se lee en la portada: “composta e dedicata / al / Signor Don José Antonio Gómez / Maestro de Capella Della Santa Chiesa Metropolitana / di / Mexico. BACA, 1850. 
brillo que había gozado durante varios siglos. De hecho, el último que ostentó este importante puesto fue Mateo Manterola, entre 1815 y $1838,{ }^{23}$ quien cansado de quejarse de la deteriorada situación que reinaba en la capilla musical de la Catedral Metropolitana,${ }^{24}$ anunciaba sin pena ni gloria su retiro después de 47 años de servicio. ${ }^{25}$

Dos eventos determinantes ocurrieron hasta el año de 1854, cuando el General Antonio López de Santa Anna (*1794; †1876), ocupaba el último y el más popular de sus mandatos presidenciales. En el primero, Gómez presidió el comité que escogería la partitura del Himno Nacional Mexicano; ${ }^{26}$ y el segundo, durante la convocatoria para ocupar la dirección del Conservatorio de Música. Aquí, Gómez concursó con "profundo conocimiento" y "extraordinaria actitud", y aunque se ventiló abiertamente en los periódicos locales que había ganado la plaza venciendo al mismísimo compositor Catalán Jaime Nunó (*1824; $\dagger 1908$ ), quien se habría de inmortalizar, irónicamente, ganando el primer evento. ${ }^{27}$ Aunque tuvieron que pasar varias décadas para que el Himno Nacional acabara por ser aceptado; mientras el Conservatorio Nacional de Música, que inexplicablemente se había cancelado entonces, tendría que esperar para abrir hasta 1866.

En cuanto a su fecha de fallecimiento, esta quedó pendiente al dejar la Ciudad de México. Aquejado de una larga enfermedad y con problemas financieros, se habían especulados varias fechas, entre los años de 1860 y 1870, sobre su fallecimiento en la ciudad de Tulancingo (véase nota 2), como también dejando viuda a Guadalupe Alcántara, su tercera esposa. ${ }^{28}$ Mientras se resolvía esta incógnita, su Miserere (mencionado arriba), y otras obras suyas continuaron siendo ejecutadas en la Catedral Metropolitana como en la Catedral de Guadalajara hasta principios del siglo XX. ${ }^{29}$

23 A raíz del retiro de Antonio Juanas a España en 1815, Manterola recibe la posición de maestro de capilla. Véase $\boldsymbol{M E X}$ Mc, Actas Capitulares, Libro 72, Folios 313r-313v, 10 de enero de 1832.

$24 \mathrm{Al}$ no haber dinero para su reparación y mantenimiento, los órganos monumentales continuaron descompuestos, inclusive el archivo musical e instrumentos estaban abandonados. Véase $\boldsymbol{M E X}-\boldsymbol{M c}$, Actas Capitulares, Libro 76, Folio 84r-84v, 18 de enero de 1841; $\boldsymbol{M E} \boldsymbol{E}$ - $\boldsymbol{M c}$, Actas Capitulares, Libro 76, Folios 97v-98r, 2 de marzo de 1841.

25 Véase $\boldsymbol{M E X}-\boldsymbol{M c}$, Actas Capitulares, Libro 75, Folio 38r, 12 de mayo de 1838.

26 Los otros miembros fueron Agustín Balderas y Tomás León (*1826; †1893), quienes el 9 de agosto de 1854, declarando ganadora la obra "más digna”, la de Jaime Nunó. Véase ROMERO, 1961: 93-94.

27 Lo que es sorprendente de este caso, es de la ausencia de la partitura ganadora, el manuscrito de Nunó, del concurso para el Himno Nacional Mexicano. Véase, Partituras presentadas al concurso del Himno Nacional Mexicano, Colección Antigua en el Archivo Histórico Biblioteca Nacional de Antropología e Historia (en adelante, AHBNAH) Eusebio Dávalos Hurtado, INAH.

28 Probablemente fueron sólo dos matrimonios. El primero, se deduce por la existencia de su hijo, Alejandro, también músico. Del segundo, se confirma del certificado expedido el 9 de enero de 1854, Gómez de 59 años, previamente casado, comprometiéndose con María Guadalupe Alcántara, edad 37. La ceremonia se llevó a cabo en la Purísima Concepción del Salto del Agua, Regina Coeli, justamente unas semanas antes de dejar la Ciudad de México. Véase http://www.familysearch.org/ENG/ search/frameset_search.asp

29 No he podido confirmar este dato, véase GALINDO, 1933: 505. Pero si de los músicos de la Catedral Metropolitana que dejaron nombres y fechas en algunas partituras de Gómez. La parte de flauta de su Pasión del Miércoles Santo lleva a lápiz fechas que van del 19 de abril de 1889, al 8 de abril de 1903. 


\section{El bel canto}

A mediados del siglo pasado, Robert M. Stevenson — quien afirmara que "Rossini, Bellini, Donizetti y Verdi eran los dioses incontestables de la música mexicana del siglo XIX"30_ vio a Gómez como sucesor de José Mariano Elízaga $(* 1786 ; \uparrow 1842),{ }^{31}$ quien fuera reconocido por haber fundado la primera escuela de música del México Independiente. ${ }^{32}$ Con gran intuición, Stevenson relaciona las Variaciones sobre el tema del jarabe mexicano (1841), ${ }^{33}$ de Gómez con las Danzas Eslovacas de Antonín Dvořák y las Danzas Noruegas de Edvard Grieg, como el primer ejemplo en México de la aportación de temas populares al idioma clásico. ${ }^{34}$

Para 1964, Thomas Stanford y Lincoln B. Spiess tuvieron que coordinarse con el Museo Nacional de Antropología e Historia, para microfilmar — se dice así de fácil— los cientos de manuscritos musicales que secretamente había conservado la Catedral Metropolitana. ${ }^{35}$ Colosal trabajo, que inmediatamente hicieron participe de sus primeros resultados en Some Preliminary Information Concerning Certain Mexican Musical Archives (1966), pero en donde sólo aparece una escueta referencia a Gómez que en paréntesis dice: "(b.1805-d.1870; prolific; also theorist)" ${ }^{36}$ La reivindicación ocurre tres años más tarde, cuando publican sustanciales adelantos en An Introduction to Certain Mexican Musical Archives.

Los investigadores norteamericanos comentaban que durante la transición de estilos musicales, entre los siglos XVIII al XIX, las obras de Gómez se caracterizaron por delinear un sentimiento-romántico superficial. Aunque lo reconocen por tener cierta importancia, se decide no recomendar ningún festival de su autoría. ${ }^{37}$ Curiosamente, cierra en esta publicación dos positivas opiniones que valen la pena retomar: "In general, however, the period after 1825 represents a rapid decline in quality of church music in Mexico [...] in Mexico City there was still competence through Maestro José Antonio Gómez in the midcentury". ${ }^{38} \mathrm{Y}$ el último comentario, que incluye detalles importantes, entiéndase sus métodos:

[Gómez] Maestro de Capilla, M[éxico], mid-nineteenth century. One of the more prolific composers in Mexico. Style generally unimaginative, but some interesting experiments (parts for two organs, pianoforte, etc.). Author of three, possible more, theoretical works: Instructor Filarmónico Semanario Musical, Tomo 1o, Mexico, 1843; El Inspirador Permanente, Gran Método de Música Vocal, Mexico, 1844; Instructor Filharmónico, Nuevo Método para Piano, Mexico, n.d. (ca. 1855). ${ }^{39}$

30 STEVENSON, 1952: 192.

31 Véase Ibíd.: 191.

32 Véase PAREYÓN, 2007: 17.

33 La única grabación que conozco de esta obra viene en Cyprien Katsaris, 2007.

34 Véase PAREYÓN, 2007: 185.

35 Spiess and Stanford no fueron los primeros en investigar dichos manuscritos. Ya en 1934, Gabriel Saldívar había mencionado la existencia de ellos: "hemos podido obtener de las Iglesias, porque en su mayoría no tienen Archivos Musicales [...] La Catedral Metropolitana sí tiene un gran Archivo, quizá el más rico y el más grande de América Colonial” SALDÍVAR, 1934: VII.

36 SPIESS. STANFORD, 1969: 6.

37 Intrigante comentario que cambió inmediatamente al visitar a Stanford y presentarle parte de la transcripción de una de las obras de Gómez, precisamente una festividad para los Maitines. Ibíd.: 15.

38 Ibíd.: 43.

39 "[Gómez] Maestro de Capilla M[éxico], mediados siglo XIX. Uno de los más prolíficos compositores en México. Estilo en general sin imaginación, pero algunos interesantes experimentos (partes para dos órganos, pianoforte, etc.) Autor de tres, tal 
Para nuestra fortuna, Stanford continuó empeñado en revisar los otrora tomados microfilms para completar su extenso catálogo que finalmente alcanzó a ser publicado en el 2002 — y hasta ahora nuestra única herramienta de consulta sobre estos acervos-.$^{40}$ Considerando sus investigaciones, Stanford coincide como lo había señalado anteriormente Saldívar, en atribuir a la colección de música religiosa del archivo de la Catedral Metropolitana como la más grande y rica del mundo Hispano. Hay que admitir que en algo debió de haber contribuido Gómez a este valioso legado musical. Es momento de acercarse y revisar los documentos correspondientes al periodo del México Independiente.

\section{Correspondencia, Actas Capitulares y Periódicos}

En el $\mathbf{M E X}$-Mc se encuentra Correspondencia, Peticiones a Vacantes de Ministros y Otros, 18301882 Expedientes, sección que contiene las cartas que Gómez dirigió al principal cuerpo administrativo de la Catedral Metropolitana: el Cabildo. No son para tomarse a la ligera, ya que la lectura de estas cartas ofrece desde aspectos laborales hasta personales de la relación directa de un músico con la más importante Iglesia de México. Al mismo tiempo, muestra facetas poco conocidas de su oficio musical: sus inicios como tercer organista, su reiterada intención —entonces poco creíble - en renunciar, su inevitable ascenso de segundo a primer organista, sus varias y descriptivas licencias para ausentarse por cuestiones de salud y ahora sí su irrevocable retiro de la Catedral Metropolitana.

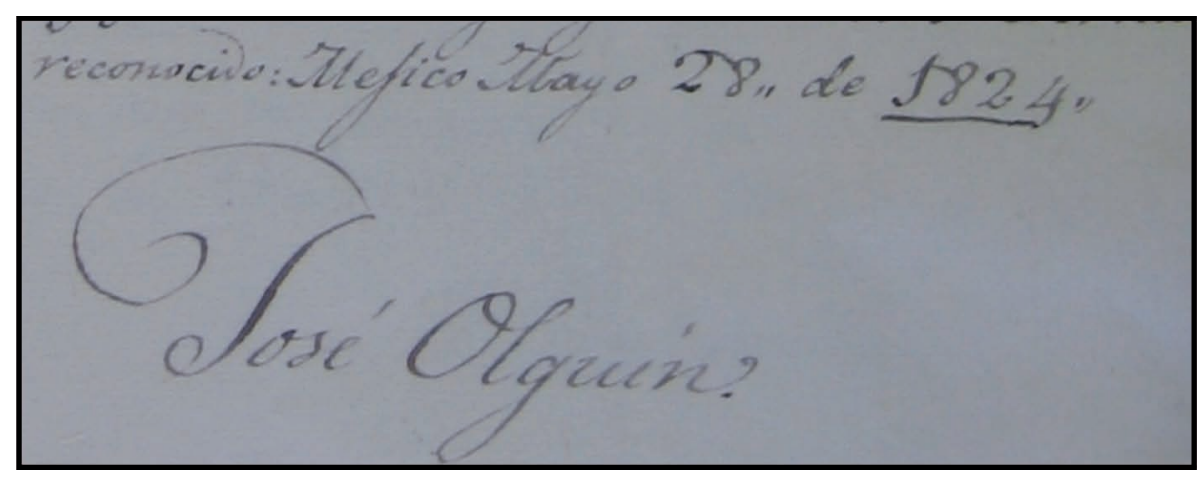

Figura 1. Rúbrica como José Olguín que Gómez dirige al Cabildo Metropolitano MEX-Mc, Correspondencia, 28 de mayo de 1824. Fotografía del autor, 2008 40 Véase STANFORD, 2002: XV. 
La primera carta, fechada en mayo de 1824, es peculiar por su rúbrica: "José Olguín” (Fig.1). Posiblemente el excepcional uso del apellido materno haya sido para evitar confusión con un homónimo dentro del mismo ámbito laboral. Pero lo que más interesa es el contenido del texto (véase abajo), donde un adolescente, de apenas 19 años y "aún muy niño", cuestionaba quién era la autoridad, si su inmediato superior, el organista José Cataño quien se decía estar enfermo pero que seguía dando órdenes o, si el mismo Cabildo, quien debía ciertamente de imponer su jerarquía. Es decir, el joven Gómez evidenciaba sin empacho los abusos de su colega ante las autoridades correspondientes para que así tomaran papeles en el asunto, como lo demuestra la misiva.

Ilmo. y V. Sor. Dean y Cabildo.

La necesidad de ver a mi persona abatida ya por un lado, ó ya por otro, me obliga con el debido respeto presentar ante V.S.I. el haver pedido Dn. José Cataño permiso para retirarse por enfermo el Miércoles en la mañana; y al mismo tiempo prevenirme uno de los Sres. encargados de la Chantria qe. tocara el órgano hasta concluir la Semana, se venga á presentar el viernes, y mandarme decir qe. él iría á tocar, yo no tengo que obedecer más qe. á V.S.I. y á los Principales del Coro, de suerte que si con otro sujeto huviera dado creeria yo sin duda no huviera conseguido su intento, si la enfermedad no es de gravedad por qe. se me obliga á que trabaje como actual Organista, y si es de gravedad por que se viene á presentar, á lo que bien se deja entender que Dn. José Cataño, lo que pretende es escaparse de todas las funciones clásicas.

Por tanto suplico á V.S.I. se sirva ver esto con atención y justicia á cuya gracia vivirá eternamente reconocido: Mejico Mayo 28, de 1824

José Olguín [rúbrica]

Transcripción de la carta que José A. Gómez dirige al Cabildo Metropolitano. ${ }^{41}$

No se cuenta con la respuesta del Cabildo a la petición solicitada por el entonces joven organista, aunque todo indica que fue a su favor. Para 1827, a la edad de 22 años, Gómez recibe oficialmente del mismo Cabildo la nominación como tercer organista de la Catedral Metropolitana. ${ }^{42}$ Para mayo de 1832 el Chantre reconoce ante el Cabildo además de su labor como organista su faceta de compositor, ya que “...la nueva música del Miserere, D. José Gómez y Olguín, cuya pieza se había visto en el público con mayor aprecio....". ${ }^{43}$ Hacia fines de este año, redacta la primera de sus varias licencias para retirarse de la ciudad. ${ }^{44}$ Para inicios de 1833, y aprovechando la jubilación del segundo organista después de 35 años de

41 MEX-Mc, Correspondencia 1830-1882, 28 de mayo de 1824.

$42 \boldsymbol{M E X}-\mathbf{M c}$, Actas Capitulares, Libro 71, Folios 238r-238v, 18 de enero de 1827.

$43 \boldsymbol{M E X}-\boldsymbol{M c}$, Actas Capitulares, Libro 72, Folio 349v, 4 de mayo 1832.

44 Esta carta no existe en la sección de Correspondencia, aunque el Acta Capitular menciona su contenido, véase $\boldsymbol{M E X}$ - $M c$, Actas Capitulares, Libro 73, Folios 34v-35r, 22 de diciembre de 1832. 
servicio, el Cabildo le ofrece a Gómez dicha plaza y entre sus nuevas obligaciones están la de enseñar a “algún niño niño que quiera aprender el órgano....". Entonces Gómez dedica su más extensa carta al Cabildo para dejar en claro sus deseos de renunciar — notándolo varias veces a través del documento— a sus servicios como músico debido a la imperiosa necesidad de buscar de "otros arbitrios" para así solventar su "subsistencia y la de [su] familia". 46

Empero la vida da un giro en 1835. Se presenta una gran oportunidad ante el fallecimiento de Juan Ximénes, quedando ahora vacante la plaza de primer organista de la Catedral Metropolitana. ${ }^{47}$ Aparentemente, los problemas personales que Gómez había con insistencia descrito dos años atrás parecen haberse resueltos al mostrar gran interés para competir en dicha posición. ${ }^{48}$

\section{Puesta la mesa, cuestión resuelta}

Ya para estos tiempos, dada su calidad y experiencia, hacían de Gómez el candidato ideal para ocupar la posición de primer organista, el mismo Chantre vuelve a externar su apoyo al agregar que su "instrucción era notoria [...] como por las piezas que ha compuesto en las veces que para ello se ocupó." Tal fue la impresión — como lo hubo de recordar el citado Calendario Filarmónico de 1866- que después de su célebre ejecución el Cabildo concluyó contundentemente en su sesión que "sin necesidad de las formalidades de estilos y suficientemente discutido, se procedió al nombramiento de primer organista y salió D. José Antonio Gómez con todos los votos." ${ }^{49}$

Sin embargo en 1836 hay un cambio radical en el discurso del recién nominado primer organista. El motivo principal son: sus problemas de salud. A pesar de los constantes tratamientos médicos y de sus necesarios retiros, a Gómez lo aquejaban los ataques y dolores de pecho. Con amplios detalles anatómicos, las cartas describen como causa de sus males los años acumulados en el trabajo de organista durante las frías funciones matinales de la Catedral, y apenas contaba con 31 años. Para validar cada solicitud, estas vienen acompañadas de un certificado médico que confirma las necesidades imperantes del músico. Gómez advierte que es tal la gravedad que ha llegado a vomitar sangre, y por lo mismo desea evitar un resultado "funesto".

45 Véase $\boldsymbol{M E X}-\boldsymbol{M c}$, Actas Capitulares, Libro 73, Folio 42v, 11 de enero de 1833.

46 “...la cuota que necesito para mi subsistencia y la de mi familia, me è visto precisado á buscar otros arbitrios [...] no pudiendo cumplir con la exactitud que deseo y con la eficacia que hasta aquí è desempeñado la plaza [...] se me hace preciso à mi pesar renunciarla [...] esta renuncia no tiene otro motivo que el ya expuesto, pues temo incurrir en alguna falta por atender à la vez mis otros jiros [...] quedo pronto y muy gustoso à servir à V.S.I. tiempo que tenga la bondad de ocuparme en las festividades, ò cualquier otra cosa en que me juzgue capas de servir, sin mas interés que el honor de cooperar cuanto está de mi parte à el ilustre y decoro de esta Sta. Iglesia." MEX-Mc, Correspondencia 1830-1882, 31 de enero de 1833.

47 Véase $\boldsymbol{M E} \boldsymbol{X}-\boldsymbol{M c}$, Actas Capitulares, Libro 73, Folios 52r-52v, 26 de febrero de 1833.

48 “....sirvió anteriormente [pero] que se vio precisado à separarse por atender à negocios domésticos que exigían su personalidad fuera de esta capital [...] Pero hallándome hoy expedito, está en disposición y deseo continuar sus anteriores servicios no perjudicándole su separación involuntaria la antigüedad devida.” MEX-Mc, Correspondencia 1830-1882, 16 de julio de 1835.

$49 \boldsymbol{M E X}-\mathbf{M c}$, Actas Capitulares, Libro 73, Folio 273r, 17 de julio de 1835. 


\section{Ilmo. y V. Sor. Dean y Cabildo.}

José Anto. Gómez organista $1^{\circ}$ de esta Sta. Iglesia ante V.S.I. con el devido respeto dice: Que hallándome todavía enfermo del pecho del último ataque qe. tuvo, haviendo arrojado Sangre, y padeciendo una inflamación actualmente como lo acredita la Certificación que acompaña del facultativo que lo aviste: este le à hecho presente que si no se retira una temporada de pulsar el órgano, tendrá unos resultados funestos; por lo que se vé preciado contra toda su voluntad à ocurrir à V.S.I. para impetrar la licencia que halle por conveniente para dicha curación, por tanto à V.S.I. Suplica acceda à Su Solicitud en la que recibirá merced y gracia.

Mejico. y Agosto 25/836

José Anto. Gómez [rúbrica]

Transcripción de la carta que José A. Gómez dirige al Cabildo Metropolitano. ${ }^{50}$

Las condiciones físicas del músico no mejoran, al reparar que las cartas van apareciendo con mayor frecuencia. Para noviembre de 1836, Gómez sigue con dolores de pecho que han deteriorado su estado de salud (Fig.2). Además de las arduas labores que ha mantenido desde su infancia, aunadas a las frías mañanas, se agrega ahora como principal causa de sus males las duras temporadas de invierno. ${ }^{51}$ Ante estos argumentos, el Cabildo acepta otorgarle licencia para ausentarse, lea usted, hasta por cuatro largos meses. ${ }^{52}$

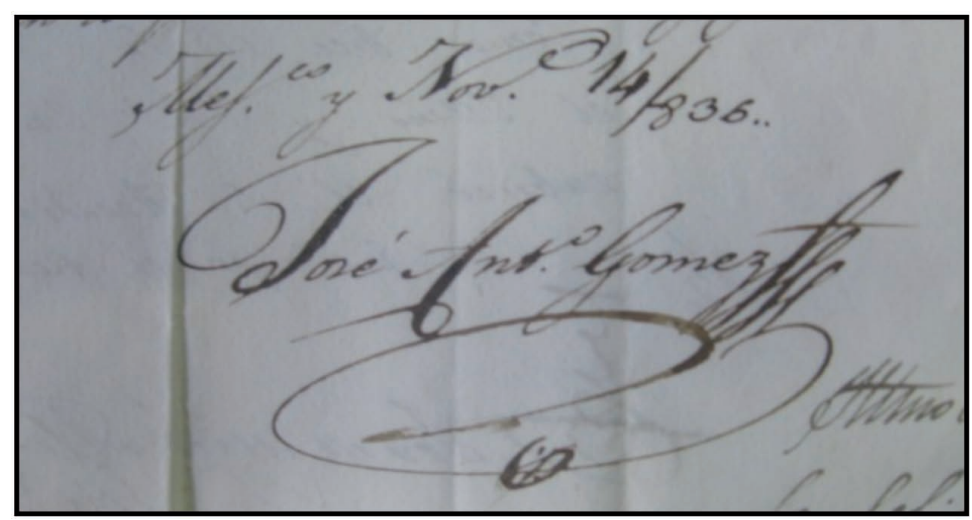

Figura 2. Rúbrica de Gómez que dirige al Cabildo Metropolitano.

MEX-Mc, Correspondencia, 14 de noviembre de 1836. Fotografía del autor, 2008.

50 MEX-Mc, Correspondencia 1830-1882, 25 de agosto de 1836.

51 “...duro trabajo que desde mi niñez è tenido, [y que] me es muy nocivo el ayre sutil, y frío que reina por las mañanas; principalmente en el tiempo de frío..." MEX-Mc, Correspondencia 1830-1882, 14 de noviembre de 1836.

52 Véase $\boldsymbol{M E X}-\boldsymbol{M c}$, Actas Capitulares, Libro 74, Folio 81v, 15 de noviembre de 1836. 
El mismo tono se mantiene en 1837: "mis enfermedades", el intenso trabajo, los dolores de pecho, y los fríos inviernos se suman como los motivos para retirarse a un lugar cálido.$^{53}$ En enero del siguiente año, Gómez pide ausentarse por seguir "enfermizo del pecho", a cuya respuesta el Cabildo le otorga otros dos a tres meses de descanso. ${ }^{54}$ En 1838, a pesar de su lamentable estado, se le otorga un aumento de sueldo por el "empeño en el cumplimiento de su obligación, y por que ha compuesto varias piezas para la orquesta, pudiendo ser el director de esta [...] [por lo que] como encargado del arreglo de la orquesta proponer en el plan el aumento que puede hacérsele á Gómez como director de ella." 55

Y todavía falta revisar 1842, el cual se le presenta como un año complicado. Gómez suscribe cinco cartas, cada una con certificado médico incluido, al Cabildo entre los meses de febrero a agosto, exceptuando abril y junio. Su insistencia se debe a que un mes no es suficiente para recuperarse. En febrero relata que "...hallándome bastante enfermo como lo acredita el adjunto certificado y necesitando de disfrutar unos ayres puros, y una curación radical. ${ }^{{ }^{56}}$ En marzo, Gómez recuerda que hace falta otro mes. ${ }^{57}$ Es de notar que en este momento, el Cabildo siga aceptando las solicitudes del enfermo, otorgándole mes y medio de descanso. ${ }^{58}$ En mayo, se queja que el tratamiento fue interrumpido por un nuevo y repentino "ataque al Pulmón", solicitando nuevamente "de mas licencia para su curación". ${ }^{59}$ En julio, continúan los pedidos ya que "para su completo restablecimiento necesita de un poco mas de tiempo como lo acredita el adjunto certificado" ${ }^{60}$ Relativa variante en agosto, a raíz de un nuevo decreto, que sugiere que alguien ocupe su posición en caso de patitur, ausencia del trabajo debido a enfermedad. Sus molestias son tales, que el profesor González, "sujeto bastante instruido", es mencionado como el indicado para remplazarlo en su plaza. ${ }^{61}$ Sobre sus enfermedades y remedios, esta sería la última carta que Gómez dirigiera al Cabildo Metropolitano.

53 "suplico rendidamente á la bondad de V.S. y se sirva continuarme el permiso de que toque por mi en las misas de temprano de mi cuenta y riesgo [...] deviendo esta indulgencia por el tiempo necesario hasta mi total restablecimiento." $\boldsymbol{M E X}$ - $\boldsymbol{M c}$, Correspondencia 1830-1882, 20 de julio de 1837.

54 "Que hallándome muy debilitado, y enfermizo del pecho por lo mucho que he trabajado, me portan los catarros principalmente en la estación de los fríos [...] tenga á bien darme licencia, para ir á un temperamento caliente por dos o tres meses." $\boldsymbol{M E X}-\mathbf{M c}$, Correspondencia 1830-1882, 8 de enero de 1838.

$55 \boldsymbol{M E X}-\mathbf{M c}$, Actas Capitulares, Libro 75, Folio 39v, 25 de mayo de 1838.

56 MEX-Mc, Correspondencia 1830-1882, 21 de febrero de 1842.

57 "Que no haviendole sido suficiente el mes que se le dio para su curación como lo acredita al adjunto certificado, se vé precisado á que V.S.I. se sirva prorrogar el tiempo para seguir dicha curación.” MEX-Mc, Correspondencia 1830-1882, 20 de marzo de 1842.

58 Véase $\boldsymbol{M E X}$ - $\boldsymbol{M c}$, Actas Capitulares, Libro 76, Folio 225r, 22 de marzo de 1842.

59 "Que haviendo sido interrumpida su curación por un nuevo ataque del Pulmón que tuvo en días pasados..." $\boldsymbol{M E X}$ - $\boldsymbol{M c}$, Correspondencia 1830-1882, 1 de mayo de 1842.

60 MEX-Mc, Correspondencia 1830-1882, 5 de julio de 1842. A partir de ahora, el Cabildo solo le concede un mes de licencia, véase $\boldsymbol{M E X}-\boldsymbol{M c}$, Actas Capitulares, Libro 76, Folio 262v, 5 de julio de 1842.

61 "Que impuesto del decreto del 30 del próximo pasado para que cada uno de nosotros proponga un suplente que desempeñe en nuestro patitur abierto o cerrado, al efecto propongo al Profesor D. Agustín González, sujeto bastante instruido, pues desempeña funciones en varias Iglesias, dá lecciones de Piano, es honrado y exacto en el cumplimiento de sus obligaciones." MEX-Mc, Correspondencia 1830-1882, 9 de agosto de 1842. 


\section{Ahora decide renunciar}

También está el otro lado de la moneda. El nombre de Gómez aparece en las Actas Capitulares de la Catedral Metropolitana nuevamente hasta el año de 1850, pero es evidente que su relación con el Cabildo dista de lo que alguna vez fue, la tónica es de confrontación. En enero el Chantre, figura de quien alguna vez recibiera su apoyo, ahora expresa doble queja: sobre sus ausencias y hasta del aspecto de su suplente. ${ }^{62}$ Estas últimas, las apariencias, llegan a desagradar tanto que le exigen a Gómez y a su sustituto que porten "traje decente." ${ }^{63}$ Las quejas continúan. Para 1853, se le recuerda que está obligado a enseñar a los niños infantes, lo que debería de tomarse como una directa afronta para un profesor con tal trayectoria. ${ }^{64}$ En 1858, Gómez presenta nuevamente solicitud de licencia para ausentarse, pero la respuesta es tajante: el primer organista no puede retirarse de sus servicios ni siquiera una semana. Ahora le toca a Gómez soportar sin importar su jerarquía. Como ví me ven, habrá pensado en 1862, cuando Mendoza, el segundo organista, protesta que no le han pagado por las funciones extras. ${ }^{65}$

Parece que le llueve sobre mojado. Su situación se ha vuelto tan problemática que hasta por terceros tiene que pagar los platos. Llega 1864, y después de 40 años de regular servicio, el Cabildo rechaza con la mano en la cintura la propuesta de Bernardo de Mendoza para jubilarse ya que "la Iglesia no puede sufragar esa clase de gastos [...] porque se abriría la puerta para que otros empleados de la Iglesia hicieran iguales solicitudes, como por ejemplo el Sochantre, [y por supuesto,] el organista Gómez". ${ }^{66}$

Los tiempos requieren medidas extremas y en 1865 irrumpe la confrontación. El 2 de mayo, el Secretario informa que el organista no puede "ausentarse por largo tiempo", además de recordarle que ya se le había dicho exactamente lo mismo tiempo atrás, en 1858. La amenaza no puede ser más clara, "si en el mes dejaba de tocar el órgano personalmente ocho días, se tendría por vacante la plaza [y que se] procederá la provisión de la plaza de organista sin que procediese ningún oficio." ${ }^{67}$ Así de tensa era la relación entre Gómez y el Cabildo Metropolitano.

Hay que reconocer que Gómez no era ningún ingenuo, todo aparenta que tenía en claro lo que le podía ocurrir. Lo siguiente debió haber sido la gota que colmó el vaso. Dos semanas después y sin perder tiempo, el Cabildo ya anda buscando "sugeto que se haya de nombrar en lugar de D. Antonio Gómez." ${ }^{68}$ El 19 de mayo, sin ningún interés de hacer acto de presencia, un orgulloso y decidido primer

62 Véase $\boldsymbol{M E X}-\boldsymbol{M c}$, Actas Capitulares, Libro 83, Folios 25r-25v, 10 de enero de 1850.

$63 \boldsymbol{M E X}-\mathbf{M c}$, Actas Capitulares, Libro 83, Folio 26r, 11 de enero de 1850.

64 El "Sr. Chantre dijo que Gómez niega la obligación que como Organista tiene de enseñar á los niños infantes [...] es fuera de duda que tiene obligación de enseñar á los niños infantes". MEX-Mc, Actas Capitulares, Libro 84, 165v-166r, 12 de julio de 1853.

65 MEX-Mc, Actas Capitulares, Libro 87, Folios 112-113, 6 de junio de 1862.

$66 \boldsymbol{M E X}-M c$, Actas Capitulares, Libro 87, Folio 392, 20 de diciembre de 1864

$67 \boldsymbol{M E X}-\mathbf{M c}$, Actas Capitulares, Libro 88, Folio 40, 2 de mayo de 1865.

$68 \boldsymbol{M E X}-\boldsymbol{M c}$, Actas de Cabildo, Libro 88, Folio 50, 16 de mayo de 1865. 
organista envía su irrevocable renuncia al Cabildo, la cual es llanamente aceptada.$^{69}$ De esta forma, finalizan más de cuatro décadas de servir como uno de los músicos más activos de la Catedral Metropolitana.

Curiosamente nos enteramos que apenas unos días atrás, el 24 de abril, cuando la Catedral de Tulancingo había quedado apenas instalada, ${ }^{70}$ había aparecido en el periódico local una larga lista de nombres que hacia el final todavía aclara que se "me pasaba decir á vdes., que D. José Antonio Gómez, organista que fue por muchos años de la Catedral de México, lo es en la actualidad de la de Tulancingo." ${ }^{.71}$ Es decir, Gómez ya estaba tranquilamente instalado en Tulancingo, inclusive había contraído nupcias hacía apenas unas semanas, mientras andaba impugnando al mismo tiempo, su posición de servidor ante el Cabildo de la Catedral Metropolitana.

\section{Calendario de las Señoritas megicanas}

El epígrafe con el que abre este ensayo data de 1840. Tomada de la biografía de Gómez —y la única de un músico en los cuatro volúmenes que publica el Calendario de las Señoritas Megicanas—, nos muestra los logros alcanzados por el primer organista de la Catedral Metropolitana, y apenas contaba con 35 años. Los datos que aparecen en esta biografía son fundamentales ya que Francisco Sosa retomaría en 1884 - y varios después de fallecido el músico — para incluirlas en sus Biografías de Mexicanos Distinguidos, y que por cierto más adelante la literatura de la música mexicana recogiera para regularmente hacer eco, incluyendo las fallas que Sosa agrega a los años que el músico todavía habría de vivir, es decir, más de la mitad de su existencia.

En esta primigenia biografía de 1840, Gómez — quien asumimos como el responsable del texto— da cuenta al lector, entre otras cualidades mencionadas arriba, de ser "ornamento de su patria" por su "rara habilidad en el arte de la música". Es importante señalar que incluye también la primera imagen que se conoce del joven, por cierto además de andar bien vestido, se ve en excelente estado físico (Fig.3). Tal extrañeza es evidente al remarcar los claros contrastes. Recuérdese cuando el primer organista insistía constantemente al Cabildo Metropolitano de sus continuas enfermedades con sus necesarios retiros fuera de la ciudad; mientras tanto, en estos mismos años, entre 1839 y 1843, habría de comenzar su periodo más activo en la sociedad capitalina, como se verá a continuación.

69 Agustín de Mendoza es el nuevo primer organista de la Catedral Metropolitana. MEX-Mc, Actas de Cabildo, Libro 88, Folios 51-52, 19 de mayo de 1865.

70 Véase $\boldsymbol{M} \boldsymbol{E} \boldsymbol{X}-\boldsymbol{M c}$, Actas Capitulares, Libro 88, Folio 38, 24 de abril de 1865.

71 La Sociedad. Periódico Político y Literario (México, 24 de abril de 1865): 1. 


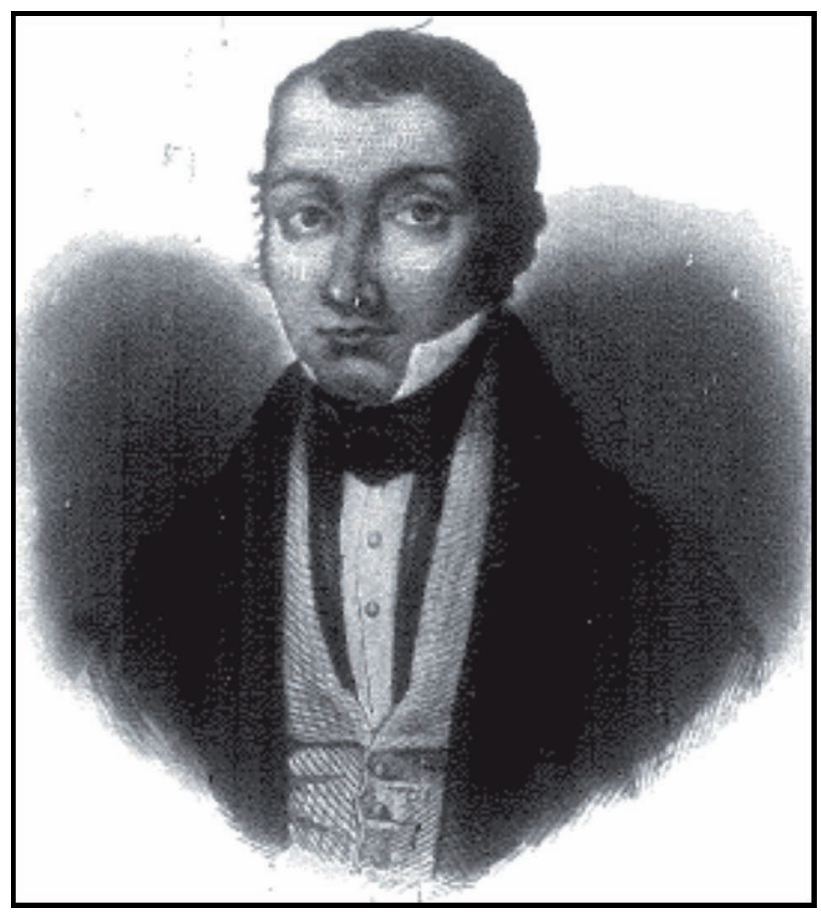

Figura 3. José Antonio Gómez (1840).

\section{El Conservatorio Mexicano}

Sin lugar a dudas la actividad de Gómez en la capital del México independiente es la de un pionero en el ámbito de la música secular. En noviembre de 1839, ocurre gran acto público en el Palacio de Minería en el que Gómez presenta, y el título lo dice todo, su Prospecto y Reglamento de la Gran Sociedad Filarmónica y Conservatorio Mexicano. ${ }^{72}$ El discurso en este Prospecto comienza elogiando a las clases sociales, ${ }^{73}$ quienes degustan de las óperas interpretadas por aficionados y de cuya música se ha diseminado rápidamente en la capital mexicana. A pesar de las "disensiones civiles que han desgarrado las entrañas de la patria", frecuentes en este periodo, se ha permitido el progreso en las artes, entre ellas a la música, tan capaz de dar forma al "carácter dulce" de una nación y la de sus individuos. He aquí parte del noble y ambicioso discurso.

72 Véase GÓMEZ, 1839.

73 Galindo se atreve a afirmar que en el corazón de Gómez "latía el sentimiento nacionalista y una cierta repugnancia a las costumbres coetáneas de apegarse demasiado al arte extranjero, tanto por la admiración prodigada a los artistas extraños, como por el estudio de su música y de su técnica. Esta idea, según lo expresó el mismo Sr. Gómez, fué la base de la fundación de su Sociedad Filarmónica y de su Conservatorio adjunto". GALINDO, 1933: 506. 
Observando yo por la historia, por la inducción y por la experiencia, que el carácter dulce del pueblo mexicano le hace el más apto para la adquisición y cultivo de las bellas artes como de las bellas letras, hasta el punto de que podría llegar a no necesitar de otro algún pueblo y a rivalizar con todos los demás, y siendo, por último, constante, que menos prometía y menos importancia tuvo en su principio el Conservatorio de Madrid, concebí el proyecto de realizar éste pensamiento sobre escala más extensa. ${ }^{74}$

Gómez apunta hacia la falta de un espacio para esta necesaria disciplina en la República Mexicana; por ende, como en cualquier nación que se dice ser civilizada, esta requiere de una institución educativa. ${ }^{75}$ Pero el discurso no solamente está cargado de tintes demagógicos — de alguna manera tenía que ganarse el apoyo de las clases acomodadas $-{ }^{76}$ ya que este tiene también su lado pedagógico. Para demostrar su potencial musical, sobresalen como ambiciosos ideales los nombres de Haydn, Mozart, Rossini, Bellini y Donizetti, y con ellos apuesta por un sistema moderno y personalizado en pos de promover las "buenas costumbres de los pueblos", independientemente de sexo, o clase social. Empero, este ambicioso proyecto de conservatorio, en el propio domicilio del director, ${ }^{77}$ estuvo solamente activo hasta $1843 .{ }^{78}$

El objetivo de la Gran Sociedad Filarmónica era, además del reconocimiento del público capitalino, de conseguir financiamiento para su Conservatorio. Para mayor impacto social, se contempla ofrecer dos conciertos al mes, en los que tomarían parte los miembros de la Sociedad, es decir, los "socios de mérito, socios fundadores, suscritores y alumnos." A pesar de que hubo que suspender uno de estos conciertos, debido a la "indisposición de algunos profesores", Gómez no desaprovechó la contrariedad y programó un "GRAN BAILE [...] [en el que pudieran] llevar las señoras y caballeros trajes de fantasia". 79

\section{Los métodos musicales y nuevas revelaciones}

En 1832, Gómez ya había publicado su Gramática Razonada, con re-ediciones posteriores en 1846 y $1864 .{ }^{80}$ Este pequeño tratado teórico (de $18 \mathrm{cms}$. de alto por $11 \mathrm{cms}$. de ancho para cómodamente llevarse en el bolsillo del estudioso), está escrito en forma de diálogo. En el participan el Discípulo, quien guiado por su Maestro, gradualmente ofrecen lecciones básicas sobre notas, llaves, figuras, compases, accidentes, incluyendo la sintaxis de la música (sonido), seguido de modos, mayor y menor para finalizar con la teoría de la música. Por supuesto, es el lector quien asume el papel del discípulo para enseñarse y entender a su ritmo sobre el arte sonoro.

74 En opinión de Olavarría, el último acontecimiento notable del año se llevó a cabo en el Colegio de Minería el 15 de diciembre de 1839, donde el profesor Gómez pronunció sendo discurso sobre la fundación de la Gran Sociedad Filarmónica. Véase OLAVARRÍA y FERRARI, 1895: 365.

75 José Mariano Elízaga había fundado en 1825 el primer conservatorio del México Independiente, pero parece que sólo estuvo abierto unos cuantos años antes de que su director se mudara a Guadalajara. Véase Romero, 1934: 100.

76 El Calendario de las Señoritas megicanas (1840) también incluye biografías de dos mujeres estudiantes de Gómez y de la clase acomodada: Doña Fernanda Andrade y Doña María Dorotea Losada. Véase Calendario, 1840: 121-126, $267-271$.

77 En la casa 15 de la Calle de Santa Clara (hoy como Tacuba) a dos cuadras al poniente de la Catedral Metropolitana.

78 Véase PAREYÓN, 2007: 99.

79 Diario del Gobierno de la República Mexicana (México, 21 de marzo de 1840): 4.

80 Véase GÓMEZ y OLGUÍN, 1832. También, parte de este tratado es revisado en FLORES, 1986: 135ss. 
Ahora que, a la luz de recientes revelaciones, lo menos es confesar asombro al evidenciar que el autor de Gramática no es quien aparece en la portada de 1832 — y por evidentemente en las subsiguientes que aparecieron más adelante-. Es decir, esta Gramática ha sido todo este tiempo una copia. El original, fue publicado 11 años atrás en Madrid, y tiene como responsable a Federico Moretti y Cascone (*1769; †1839). ${ }^{81}$ Ana Carpintero Fernández es quien ha investigado a este personaje a fondo. ${ }^{82}$ Lo que ella nos dice de sus orígenes nos ilustra sus facetes, inclusive extra-musicales. Nació en Nápoles, y que por circunstancias políticas se decide nacionalizar como español. Moretti tenía la "extraordinaria habilidad para las relaciones sociales y diplomáticas, por conocer cinco idiomas (italiano, español, portugués, francés e inglés), y por las relaciones de su familia en la corte de los zares." 83 Además, como militar, alcanzó el grado de Mariscal de Campo de los Ejércitos Nacionales. Ya en los terrenos de la música, practicó desde su juventud el canto y la composición, pero fue como guitarrista y escritor de métodos musicales donde Moretti alcanzó renombre. ${ }^{84}$

Retomando los métodos, una década después de Gramática — la versión de Gómez- aparecieron como pan caliente los demás títulos. Fue el periódico en boga, El Siglo Diez y Nueve, el forum para publicitar sus métodos. En julio de 1843, a dos columnas aparece su Inspirador Permanente. Gran Método de Música Vocal. ${ }^{85}$ Pareciera razonable que este método, ${ }^{86}$ como parte de su Conservatorio, se dispusiera en secciones semanales para su expendio al público, además la columna incluía suficiente información para adquirir el método fuera de la capital. Por cierto, el contenido de la nota en El Siglo Diez y Nueve es muy similar al presentado en su Prospecto.

Que el buen gusto progresa en la república, es una verdad que todos palpamos. Los nuevos edificios que se construyen, el empeño con que se buscan los cuadros de grandes artistas, el interés que inspiran las esculturas de mérito, no dejan duda de que va en aumento la estimación de las artes encantadoras. Sin embargo, parece que la música es entre las bellas producciones la que más afecta hoy á todos los mexicanos. $^{87}$

Como parte del espíritu de apertura que se respiraba en el México Independiente, Gómez reconocía la presencia de la tradición Europea en una capital ávida de escuchar música. ${ }^{88}$ Prueba de "las artes encantadoras" era la popularidad que tenía el forte-piano. Apenas un extraño lujo una década anterior a la Independencia, era en este tiempo común que las "familias acomodadas" tuvieran la capacidad financiera

81 MORETTI y CASCONE, 1821.

82 El rey [de España] le autorizó, en 1828, a utilizar el título de Conde de Moretti, concedido a su familia por el Gran Duque de Toscana." CARPINTERO FERNÁNDEZ, 2009: 121. También, como parte de su tesis doctoral, véase CARPINTERO FERNÁNDEZ, 2010: 79-110.

83 CARPINTERO FERNÁNDEZ, 2009: 117.

84 Véase CHASE, 1959: 63.

85 GÓMEZ y OLGUÍN, 1843.

86 Gómez basó su método, como bien dice aunque parcialmente, en las vocalizaciones del tenor italiano Marco Giulio Bordogni $(* 1789 ; \dagger 1856)$.

87 El Siglo Diez y Nueve (México, 11 de julio de 1843): 4.

88 Partituras de Beethoven estuvieron a la venta en México hacia fines del siglo XVIII; aunque fueron prohibidas por considerarlas "peligrosas para la estabilidad de la Nueva España", continuando sus ventas omitiendo el nombre del compositor. Véase SORDO, 1971: 577. 
de poseer uno de estos instrumentos de teclado. Es más, Gómez concibe su método teniendo en mente al público en general:

Con el objeto de que los mexicanos puedan poseer una obra completa y la mas exacta á mi parecer, me he propuesto publicar un Periódico de Música vocal, y para que sin grandes desembolsos se consiga este intento, entre hacer las publicaciones por cuadernos con sus respectivas carátulas, ó por pliegos sueltos, he preferido lo segundo; porque aunque no sea lo que se presenta de una manera mas vistosa, sí es lo mas cómodo para muchos de los aficionados á la música, que por las penurias de nuestra época no pueden hacer mas que cortas exhibiciones. ${ }^{89}$

La estrategia de Gómez parece ser evidente, mantenerse presente en la sociedad mediante los varios anuncios que de sus publicaciones van apareciendo. En 1844, el Inspirador Permanente, ya casi completo, se anuncia ahora que sólo saldrá los viernes para su venta, con la posibilidad de comprarlo si el interesado requiere uno o varios de sus números anteriores. ${ }^{90}$

No hay duda de que Gómez imprime su propio sello distintivo en estas lecciones al hacerlas también suyas, como cambiar de tonalidad, modificar motivos rítmicos, alterar el sentido del texto al traducir al español su versión. Así que, ¿cómo habría de entenderse cuándo nos dice: para "cuyo fin estractaré de los autores más célebres en esta materia”? ¿Habrá querido plantear, entre líneas, que la primera parte del Instructor, lecciones 3 a la 24 de las primeras 25, pertenecen al conocidísimo compositor y cantante italiano Nicola Vaccai $(* 1790 ; \dagger 1848)$ ?

Viajero incansable, poeta de vocación, Vaccai intentó en varias ocasiones alcanzar el éxito, exiguo por cierto, como compositor de óperas. Para su poca fortuna, vivió a la sombra de Rossini —a quien conoció de cerca-, el más celebre representante del bel canto. De la casi veintena de óperas que Vaccai logró escribir, Giulietta e Romeo (1825) fue la única obra maestra que tuvo éxito fuera de Italia — hasta en México fue interpretada en tres ocasiones entre 1841 y 1857 -.${ }^{91}$ Luego, con el advenimiento de Bellini en el escenario, su suerte decayó una vez más. Para 1830, Vaccai abandona una vez más los escenarios para así concentrarse en la enseñaza, primero en Paris, y más tarde en Inglaterra. Finalmente en Londres goza de cierto renombre como maestro y compositor de música de salón, y es precisamente durante esta época cuando aparece el reconocido Metodo pratico di canto italiano per camera diviso in 15 lezioni (London, 1834). ${ }^{92}$ El Metodo pratico de Vaccai, se convirtió desde el momento de su publicación en uno de los métodos vocales más populares que se han escrito, mediante sus numerosas traducciones contando en su haber más de 40 ediciones. ${ }^{93}$

89 El Siglo Diez y Nueve (México, 11 de julio de 1843): 4.

90 El Siglo Diez y Nueve (Mexico, 13 de febrero de 1844): 4.

91 Según Gloria Carmona, "la compañía de la Castellan no descolló precisamente por la calidad de sus interpretaciones, en cambio dio a conocer en México gran parte de las óperas de Donizetti [...] Julieta y Romeo (1841) de Vaccai, véase CARMONA, 1984: 34.

92 Véase BUDDEEN, Grove Music Online. Oxford Music Online, http://www.oxfordmusiconline.com/subscriber/article/ grove/music/28880 (información consultada el 17 de mayo de 2012).

93 La página web del Departamento de Música Vocal de la Academia Sibelius y la Academia de Innovación Sibelius (Sibelius Academy Department of Vocal Music and the Sibelius Academy Innovation Centre) presenta un resumen de la vida del 
Para cuando el Inspirador Permanente está en proceso de completarse, Gómez anuncia ahora su nuevo título, el Instructor Filarmónico. ${ }^{94}$ El Instructor se divide, siguiendo los intereses pedagógicos y comerciales de su autor, en las dos áreas más elementales de la música: la teórica y la práctica. Algo complejo en su estructura, está se divide de la siguiente manera. Las primeras dos de tres partes del área teórica, escritas a mano, llevan por subtitulo el de Nuevo Método para Piano, donde la estudiante (fig. 4) aprenderá desde las "reglas para sentarse al piano" para así dominar aspectos de notación, llaves, ritmos y silencios, signos, ornamentos, términos musicales, modos, tono y sus divisiones, modulaciones y transiciones, como ejercicios sobre bajo figurado.

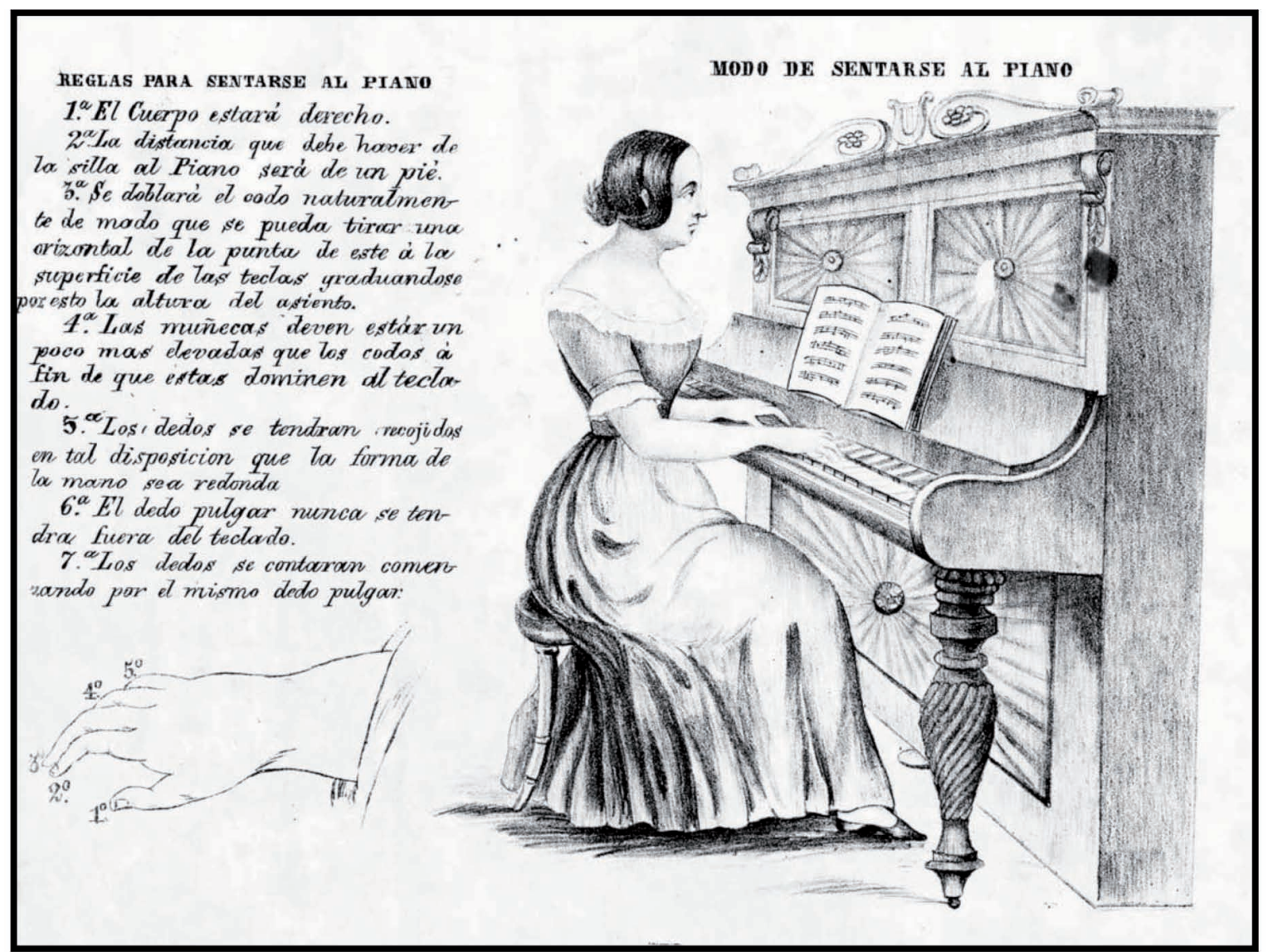

Figura 4. Gómez, Instructor Filarmónico. Nuevo Método para Piano, No. 3, Tomo $1^{\circ}, 1^{\text {a }}$ Parte (1843)

autor como de las lecciones, un estudio e interpretación del Metodo pratico di canto italiano per camera, véase: http://www2.siba. fi/vaccaj/index_en.html

94 El Fondo Reservado de la Biblioteca de la Escuela Nacional de Música de la UNAM, cuenta con estos dos tomos. 
Impreso en romanas, es la tercera parte, la más extensa del Instructor, y la que se centra en largas explicaciones y ejemplos sobre la composición y sus principales secciones: armonía y contrapunto. Entre sus más de 100 páginas con sus 18 láminas quisiera atraer la atención del elegante y bien vestido músico que aparece en la litografía, y que cualquiera sospecharía pertenece al responsable de la publicación. ${ }^{95}$ Por supuesto, esto es correcto si uno tiene a la mano la edición original de 1831, y quien tiene a su autor a Josef Joaquín de Virués y Spínola $(* 1770 ; \dagger 1840) .{ }^{96}$

Así que cuando se dice "estractado de varios Autores" habría que entender que Moretti, Vaccai y Virués forman parte de la trilogía de autores que inspiraron los métodos de Gómez. Y, ¿quién es el tercer invitado? Español de nacimiento, Virués fue aparte de teórico musical, militar, poeta y traductor de Voltaire. En 1824 publica en Madrid su Cartilla harmónica, o también bajo El contrapunto explicado en seis lecciones. Pero su obra más conocida, publicada en 1831 y la que aquí nos interesa, es La geneuphonía ó Generación de la bien-sonancia música, obra que también tuvo su versión en inglés (Londres, 1850). Según Guy Bourligueux, quien lo ha estudiado, Virués buscó explicar un principio básico, único y simple de donde toda la práctica musical puede ser deducida, y que encontró dicho camino en lo que sofisticadamente denominó como "politonogamismo", que es la aplicación del completo estudio de la armonía en un solo mes, lo que por consiguiente hacía obsoleto todos los demás métodos teóricos. ${ }^{97}$

Entre las dos versiones, La geneuphonia de Virués y la tercera parte del Instructor de Gómez, existen, más que en Gramática, sus claras diferencias. Gómez omite desde palabras, párrafos hasta páginas enteras; como actualizando en donde conviene, por ejemplo, cuando Virués afirma que la definición de Contrapunto es en su texto "nueva como toda mi teoría". Por ende, hay que eliminar el uso del posesivo que elementalmente no puede aparecer en la versión de Gómez.

De la segunda área, la práctica del Instructor, ${ }^{98}$ sigue el Periódico Semanario Musical con "una colección de piezas escogidas para piano y canto, piano y vihuela, piano y flauta, y para piano solo". ${ }^{99}$ Aquellos músicos que se habían mencionado anteriormente en su Prospecto, son ahora parte integral de su Instructor. Es aquí donde Gómez aprovecha para homenajear con una litografía del busto de Vincenzo Bellini (*1801; $† 1835)$, rodeado de los títulos de todas sus óperas. ${ }^{100}$ Es el Instructor Filarmónico para Gómez, el espacio para celebrar a la memoria de Bellini, al cual definiera como "el verdadero genio que consiste en la perfecta concordancia del genio con la parte científica del arte". ${ }^{101}$ En cuanto al área práctica del Instructor, esta ofrece desde un variado y escogido repertorio de música vocal para ejecutarse en varias combinaciones instrumentales. En su mayoría, las obras y arreglos pertenecen a compositores como Mercadante, Bellini, Donizetti, y J. Strauss, además del propio Gómez y de su hijo Alejandro (Fig.5).

95 GÓMEZ y OLGUÍN, 1843a.

96 Sería correcto asumir que también las primeras dos partes del Instructor tienen autoría. Sobre la tercera, véase VIRUÉS Y SPINOLA, 1831.

97 GÓMEZ Y OLGUÍN, 1843 b.

98 El Siglo Diez y Nueve (Mexico, 29 de septiembre de 1843): 4.

99 Entre las que hace mención aquí están La sonnambula, Bianca e Fernando, I puritani, I Capuleto e i Montesco, Norma, Il pirata, La stranera, Zaira y Beatrice di Tenda, siendo Adelson e Salvini la única que falta.

100 SALDÍVAR, 1991: 159.

101 El Siglo Diez y Nueve (México, 8 de diciembre de 1843): 4. 


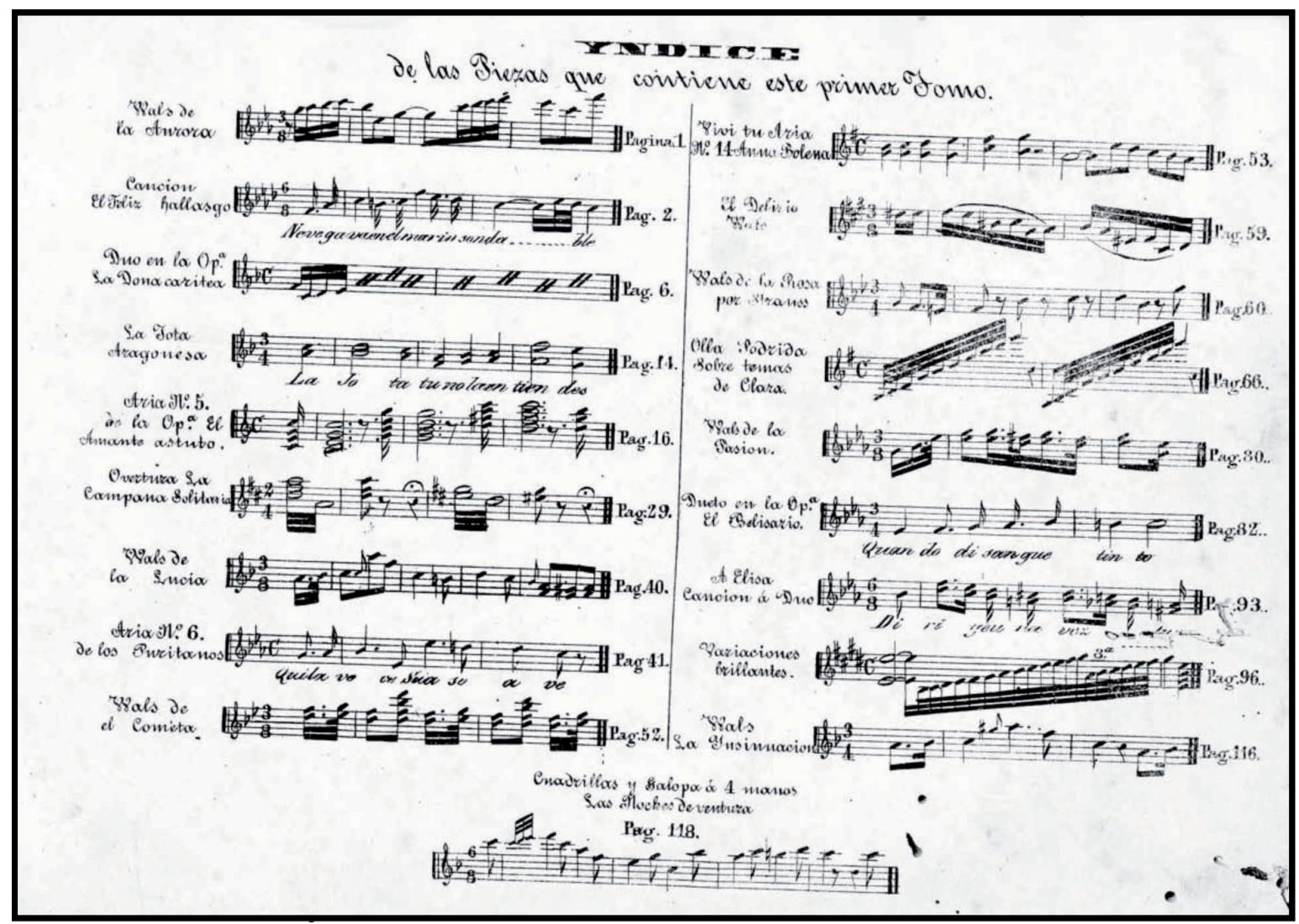

Figura 5. Índice del Instructor Filarmónico. Periódico Semanario Musical Dirigido por J. Ant. ${ }^{\circ}$ Gómez, Tomo $1^{\circ}$ (1843)

El contenido de su tercera publicación, anunciando a fines de 1843, contrasta claramente con las dos anteriores: Gran Pieza Histórica (véase Anexo), ${ }^{102}$ la cual es una re-edición escrita ya en 1821, cuando Gómez contaba con 18 años, bajo el título de Pieza Histórica (véase nota 20), y mencionada en su biografía que apareció en el Calendario de 1840. En este caso, Gómez tomó consideración especial al mandar publicar la portada de su Gran Pieza en uno de los más importantes talleres en México, la de Ignacio Cumplido (de donde por cierto se expedía el periódico El Siglo Diez y Nueve). ${ }^{103}$

102 "El taller de Cumplido se fundó en 1837 y en él se publicaron importantes periódicos, como El Siglo Diez y Nueve, además de numerosos libros, revistas ilustradas, álbumes, panfletos políticos, piezas de música y estampas de santos, entre otras publicaciones". OCHOA, 2005: 499.

103 Romero habló de esta obra en 1926 en el Primer Congreso Nacional de Música, y en 1833 en un programa de radio. Los ejecutantes fueron el profesor Eduardo Hernández Moncada, la contralto Abigail Borbolla, la soprano Dolores Pedrozo, y en el piano nada menos que Pablo Moncayo, compositor del famoso Huapango. Véase ROMERO, 1934: 144-145. 
Hay que remarcar que esta obra recapitula en detalle el fin del movimiento armado que describe la consumación de la independencia, pero sobre todo exaltando particularmente la figura de Agustín de Iturbide $(* 1783 ; \dagger 1824)$. Obra programática, cuyo texto y dibujos exhiben por sobre todo las cualidades heroicas del militar representadas en los 52 breves movimientos y un himno final que la componen. ${ }^{104}$ Hay que reconocer el ingenio de un compositor en su concepción musical siendo apenas un adolescente. Por ejemplo, la ausencia de barras de compás en el primer movimiento reflejan, siguiendo literalmente el texto, los "pensamientos" ambiguos que Iturbide atraviesa justo antes "dar el grito de Independencia", ${ }^{105}$ creando de esta manera en su contraparte musical un movimiento totalmente libre, un efecto aleatorio.

En aquel entonces, la auto-proclamación de Iturbide como Emperador de México ocasionó su inevitable exilio y por extensión cambió el destino de esta obra. Enaltecer al héroe de la Independencia podría verse como secundar sus aspiraciones imperiales, por lo que Pieza Histórica, Historia de la Independencia, o Gran Pieza permaneció pacientemente guardada durante dos décadas hasta encontrar su momento propicio. Así que para 1843, cuando Santa Anna, constante emulador de la figura de Iturbide — postura que se ha considerado como de ideología conservadora y que por cierto, ha estado ligada a los intereses de la Iglesia—, ${ }^{106}$ fungía como presidente, como también lo haría en el año de 1854 ya mencionado arriba, salieron a la venta las tres publicaciones aquí mencionadas.

Esto también se puede deducir en retrospectiva, ya que a principios de 1844, después que otro de los tantos cambios de gobierno diera lugar, los anuncios en el periódico sobre Gran Pieza desaparecieron inmediatamente (de las 20 entregas prometidas tal vez fueron dos las que se vendieron), pero no así los dos otros títulos, que políticamente inocuos continuarían publicitándose en los siguientes meses pero con discretos desplegados.

\section{CONCLUSIONES}

Este ensayo pone por un lado en evidencia lo que ha ofrecido la literatura musical del siglo XIX, para por el otro, cotejar a la luz de documentos originales provenientes de la Catedral Metropolitana como de sus propias publicaciones y musicales, y así dejar en claro episodios significativos de la vida y obra de José Antonio Gómez y Olguín. Sin embargo, aunque su calidad como filarmónico parece ineludible, hay un elemento esencial que todavía permanece ausente: su música. De todos sus manuscritos musicales, particularmente del orden religioso y hasta donde este autor tiene conocimiento, sólo un título, del cual ya hay una transcripción, ha sido investigado a fondo. ${ }^{107}$

104 La imagen de este movimiento aparece en GUERBEROF HAHN, 62 (Barcelona, 2007): 266.

105 Por cierto, en la Capilla de San Felipe de Jesús de la Catedral Metropolitana se guardan desde 1838 una urna con los restos de Agustín de Iturbide.

106 Véase la tesis doctoral de este autor, LAZOS, 2010.

107 Véase $\boldsymbol{M E X}$-SCah, Cuarto de Documentos, Música mexicana del siglo XIX, José Antonio Gómez y Olguín, Ynvitatorio, Himno y 8 Responsorios, Caja 2, Sbrs. 2-A, 2-B, Registro: CRIS 15000005. 
El Ynvitatorio, Himno y 8 Responsorios, para voces solistas, coro, orquesta y órgano, dedicada para las festividades de Corpus Christi, La Purísima y San Pedro, fue descubierto en el Archivo Histórico Diocesano de la Catedral de San Cristóbal de Las Casas (MEX-SCah), en Chiapas en 2005. ${ }^{108}$ Esta no es cualquier obra. Por sus dimensiones físicas, el Ynvitatorio es el tercer manuscrito del corpus musical de Gómez con mayor número de folios, con 521. Así que contestando a la pregunta esbozada al principio, se puede concluir que ya no están escapadas, ni desaparecidas, las fuentes musicales del siglo XIX. Por ende, ante lo expuesto hasta aquí, no hay excusa para seguir considerando a la música del México Independiente como un periodo menor al margen de la Nueva España y del México Moderno.

Además, esta tendencia comienza a ser finalmente revertida. Ahora contamos con suficientes documentos originales para entablar un diálogo renovado tanto con Gómez como con varios de sus colegas bajo propios argumentos: sus obras y sus publicaciones. Como bien lo describiera el anónimo testimonio del Calendario Filarmónico para 1866 — simpatizante por supuesto de nuestra figura- después de haber tocado para los severos sinodales de la Catedral Metropolitana las obras más difíciles para solo preguntar con una sencillez de aplomo, "casi infantil (... ¿ ¿'y es esto todo lo que hay que tocar de más difícil?’”, bien expresa el carácter del joven organista cuyo legado apenas estaba comenzando a escribirse. Ahora nos damos cuenta de que el periodo en cuestión, el siglo XIX, guarda una enorme y significativa riqueza musical aún por descubrir. Después de especular en pretérito, y solo para finalizar el presente ensayo, ahora nos mantenemos a la espera de que la obra de Gómez, como de muchos más de sus contemporáneos, regresen a nuestros oídos para una completa revaloración de los inicios de la música mexicana: el periodo Independiente.

108 La Misa y Responso (795 folios), de 1846, y sus Maytines de la Expectación (612 folios), s/f, son las otras dos obras de Gómez con mayor número de folios. Véase, STANFORD, 2002: 118-129. 
ANEXO

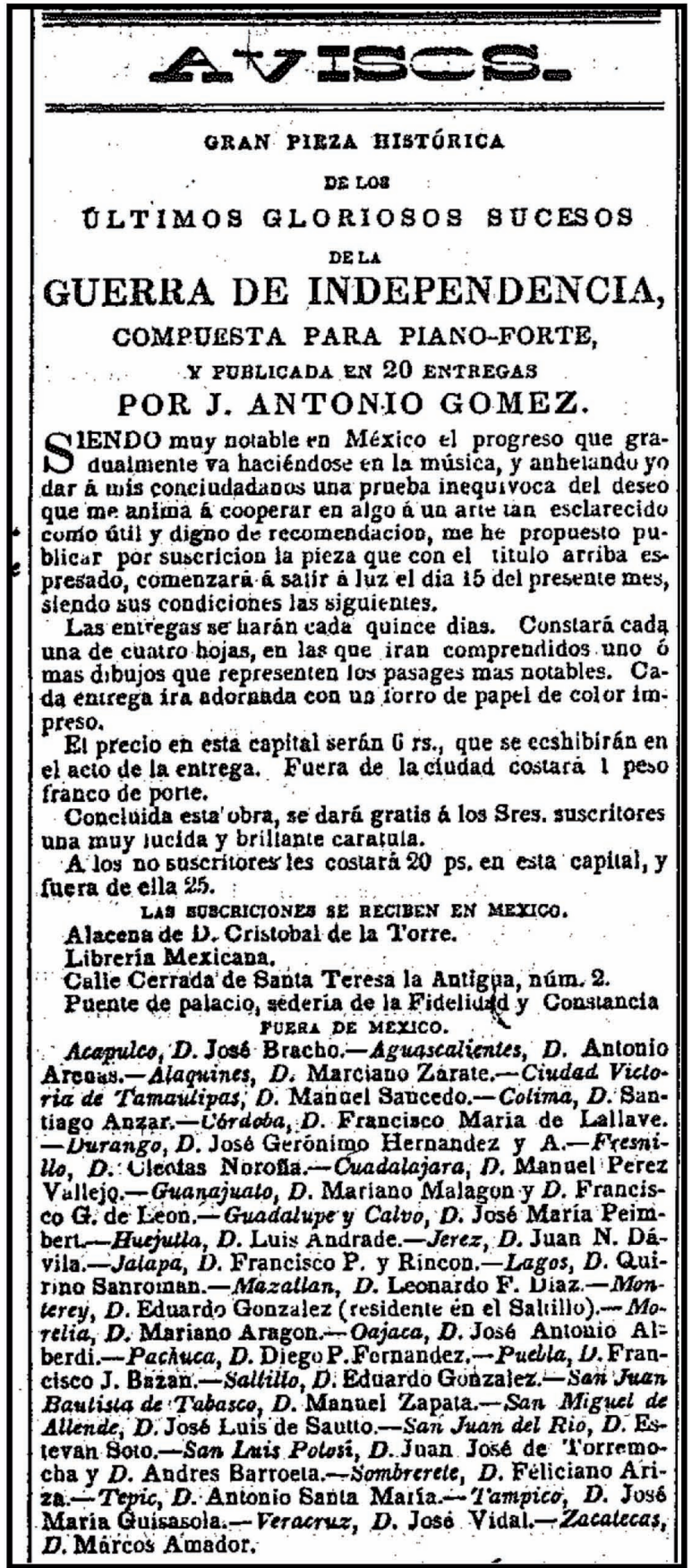

El Siglo Diez y Nueve. México, Viernes 8 de Diciembre de 1843, p. 4 


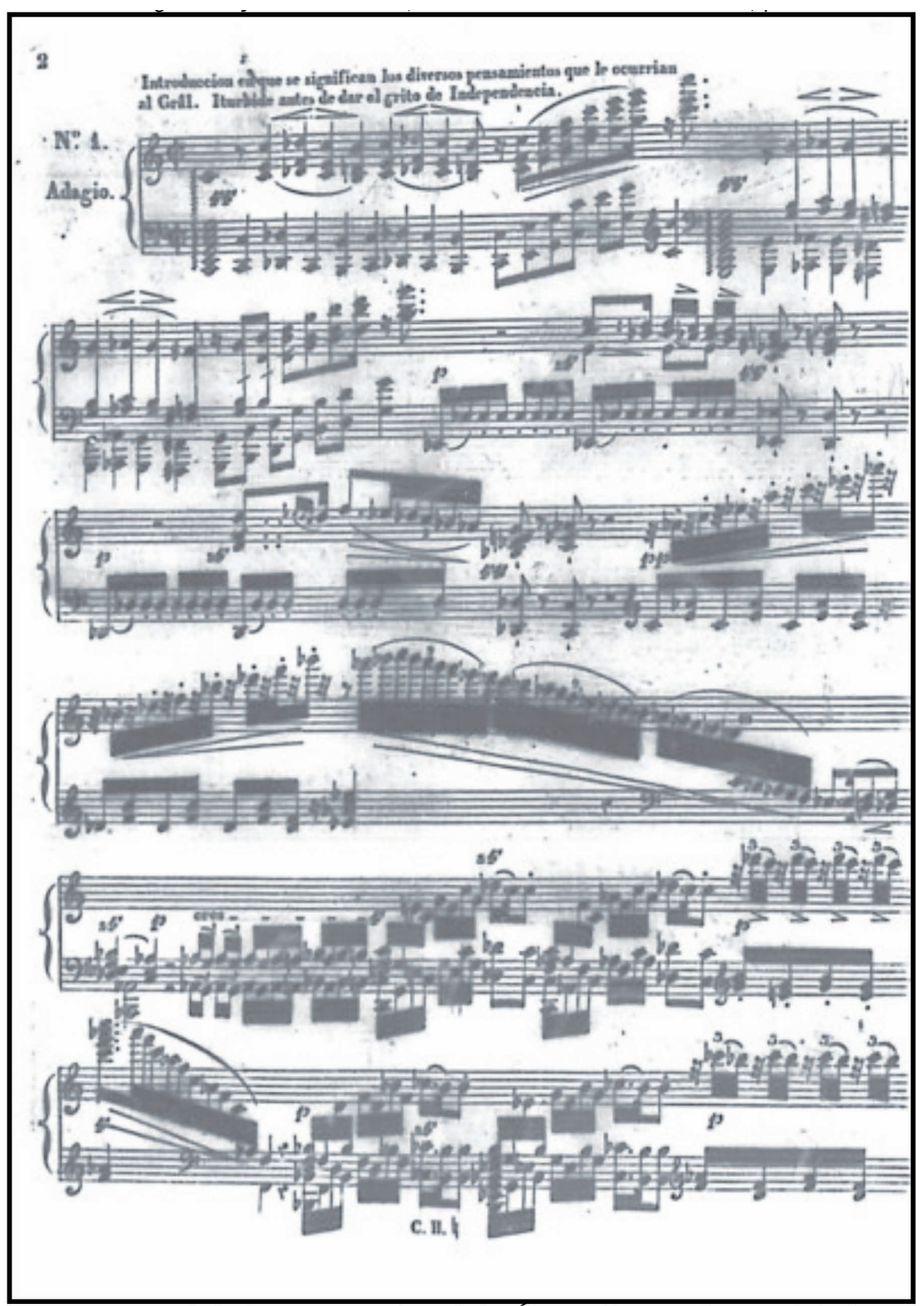

Primer movimiento de la Gran Pieza Histórica de los Últimos Gloriosos Sucesos de la Guerra de Independencia. Real Biblioteca de Madrid (E-Mp), Mus. 978 Hol. enc. h. dor. 1121926 


\section{ARCHIVOS CONSULTADOS}

MEX-Mc: Archivo del Cabildo Catedral Metropolitano de México.

MEX-SCah: Archivo Histórico Diocesano de la Catedral de San Cristóbal de Las Casas, Chiapas.

AGN: Archivo General de la Nación, México.

AHBNAH: Archivo Histórico Biblioteca Nacional de Antropología e Historia, México.

RBM: Real Biblioteca de Madrid.

\section{BIBLIOGRAFÍA}

BACA, Luis, Ave Maria, Paris, Bonoldi frères, 1850.

BAQUEIRO FOSTER, Gerónimo, Historia de la Música III. La música en el periodo independiente, México, SEP, INBA, 1964.

CARMONA, Gloria, La música de México. Historia. Periodo de la Independencia a la Revolución (18101910), México, UNAM, 1984.

CARPINTERO FERNÁNDEZ, Ana, "Federico Moretti (1769-1839) I. Vida y obra musical”, Nassarre, 25 (2009): 109-134.

CARPINTERO FERNÁNDEZ, Ana, "Federico Moretti, un enigma descifrado", Anuario Musical, 65 (2010): 79-110.

CHASE, Gilbert, The music of Spain, New York, Dover Publications, 1959.

CHÁVEZ, Carlos, La Música Mexicana, México, 1949.

FLORES, Carlos A., Music Theory in Mexico from 1776 to 1866: A Study of Four Treatises by Native Authors, Tesis de Doctorado, North Texas State University, 1986.

GALINDO, Miguel, Nociones de Historia de la Música Mejicana, México, Colima, Tipografía de "El Dragón”, 1933.

GALVÁN, Mariano impr., “Don José Antonio Gómez”, Calendario de las Señoritas Megicanas, para el año bisiesto de 1840. México, Mariano Galván impr., 1840, 195-200.

GÓMEZ Y OLGUíN, José Antonio, Gramática Razonada Musical, compuesta en forma de diálogos para los principiantes. Dedicada y publicada en México para el bello sexo, México, Imprenta de Martín Rivera, 1832.

GÓMEZ Y OLGUín, José Antonio, Prospecto y Reglamento de la Gran Sociedad Filarmónica y Conservatorio Mexicano, México, Imprenta del Iris, 1839.

GÓMEZ Y OLGUÍN, José Antonio, El Inspirador Permanente. Gran Método de Música Vocal, México, Imprenta de la Hespería, 1843.

GÓMEZ Y OLGUín, José Antonio, Instructor Filarmónico. Nuevo Método para Piano simplificado y estractado de varios Autores, Tomo I, México, C. Cerrada de Sta. Teresa la Antigua No. 2, 1844a. 
GÓMEZ Y OLGUÍN, José Antonio, Instructor Filarmónico. Periódico Semanario Musica. Colección de piezas escogidas para Piano, Canto, Flauta y Vihuela Compuestas por diversos autores, Tomos I-II, México, Calle de Sta. Clara No. 6, 1844a.

GRIAL, Hugo de, Músicos Mexicanos, México, Editorial Diana, 5ª reimpresión, 1973.

GUERBEROF HAHN, Lidia, Boletín Guadalupano, 2/33 (México, 2003): 9-11.

GUERBEROF HAHN, Lidia, Archivo musical: catálogo, México, Insigne y Nacional Basílica de Guadalupe, 2006.

GUERBEROF HAHN, Lidia, "El Archivo de Música de la Insigne y Nacional Basílica de Santa María de Guadalupe, de México", Anuario Musical, 62 (2007): 257-270.

HERNÁNDEZ, Alejandra, José María Bustamante en la capilla de música de la Catedral Metropolitana de México, Tesis de Licenciatura, UNAM, 2011.

LEHMANN, Dianne Marie, "Findings Concerning the Life and Spanish Origin of Matheo Tollis de la Rocca (c. 1710-1781)", Cuadernos del Seminario Nacional de Música en la Nueva España y el México Independiente, 3. México, UNAM, 2008, 15-23.

LAZOS, John G., "José Antonio Gómez's Invitatorio, Himno y 8 Responsorios: Historical context and music analysis of a manuscript", 2 vols., Tesis de Doctorado, Université de Montreal, 2010.

MIRANDA, Ricardo, "Reflexiones sobre el clasicismo en México (1770-1840)”, Heterofonía, 116-117 (1997): 39-50.

MONCADA GARCÍA, Francisco, Pequeñas Biografías de Grandes Músicos Mexicanos, México, Ediciones Framong, $2^{\mathrm{a}}$ ed., 1979.

MORETTI Y CASCONE, Federico, Gramática razonada musical compuesta en forma de diálogos para los principiantes por Don Federico Moretti. Dedicada al serenísimo Señor Don Francisco de Paula, Infante de España, Madrid, imprenta de Sancha, 1821.

OCHOA, Arturo Aguilar, "El Mundo del Impresor Ignacio Cumplido", Anne Staples (coord.), Historia de la Vida Cotidiana en México, vol. Iv. México, FCE, 2005, 499-526.

OLAVARRÍA Y FERRARI, Enrique de, Reseña Histórica del Teatro en México, 2ª ed., Tomo 1, México, La Europea, 1895.

ORTA VELÁZQUEZ, Guillermo, Breve Historia de la Música en México, México, Librería de Manuel Porrúa, S. A., 1971.

PAREYÓN, Gabriel, Diccionario Enciclopédico de Música en México, 2 vols., Zapopan, Jalisco, Universidad Panamericana, 2007.

PULIDO, Esperanza, Escorza, Juan José, “La música de México by Julio Estrada”, Latin American Music Review/Revista de Música Latinoamericana 8/2 (Texas, 1987): 269-292.

RADOMSKI, James, "México, 1826-1829”, Manuel Garcia (1775-1832). Chronicle of the Life of a bel canto Tenor at the Dawn of Romanticism, Oxford, New York, Oxford University Press, 2000: 211243.

ROMERO, Jesús C., José Mariano Elízaga, México, Ediciones del Palacio de Bellas Artes, 1934. 
ROMERO, Jesús C., Verdadera Historia del Himno Nacional, México, UNAM, 1961.

S/A, Calendario Filarmónico para 1866. Arreglado al Meridiano de México (México, 1865): 5658.

SALDÍVAR, Gabriel, Historia de la Música en México. Épocas Precortesiana y Colonial, México, Secretaría de Educación Pública, Impreso en los talleres de la Editorial "Cultura", 1934.

SALDÍVAR, Gabriel, Bibliografía Mexicana de Musicología y Musicografía, vol. I, México, CENIDIM, 1991.

SORDO, Carmen, "Beethoven's projection in Mexico”, Bericht Über Den Internationalen Musikwissenschaftlichen Kongress (Bonn 1970). Internationaler Musikwissenschaftlicher, Kongress, von Carl Dahlhaus, et al. Kassel, Bärenreiter, 1971, 577-578.

SOSA, Francisco, Biografías de Mexicanos Distinguidos, México, Oficina Tipográfica de la Secretaría de Fomento, 1884.

SPIESS, Lincoln B., STANFORD, Thomas E., An Introduction to Certain Mexican Musical Archives, Detroit, Studies in Music Bibliography, 15, 1969.

STANFORD, Thomas E., Catálogo de los acervos musicales de las catedrales metropolitanas de México y Puebla de la Biblioteca Nacional de Antropología e Historia y otras colecciones menores, México, Instituto de Antropología e Historia, 2002.

STEVENSON, Robert Murrell, Music in Mexico. A Historical Survey, New York, Thomas Y. Crowell Company, 1952.

VIRUÉS Y SPINOLA, Josef Joaquín de, La geneuphonía ó Generación de la bien-sonancia música, Madrid, Imprenta Real, 1831.

\section{HEMEROGRAFÍA}

Diario del Gobierno de la República Mexicana, (México, 1840).

El Siglo Diez y Nueve (México, 1843-1844).

La Sociedad. Periódico Político y Literario (México, 1865).

\section{WEBGRAFÍA}

BDH, Biblioteca Digital Hispánica: http://www.bne.es/es/Inicio/index.html (consultado el 17 de mayo de 2012).

BOURLIGUEUX, Guy, "Virués, José”, Grove Music Online. Oxford Music Online, http://www.oxfordmusiconline.com/subscriber/article/grove/music/29503 (consultado el 17 de mayo de 2012).

BUDDEEN, Julian, "Vaccai, Nicola", Grove Music Online. Oxford Music Online, http://www.oxfordmusiconline.com/subscriber/article/grove/music/28880 (consultado el 17 de mayo de 2012). 
Family Search: http://www.familysearch.org/ENG/search/frameset search.asp (consultado el 17 de mayo de 2012).

Sibelius Academy Department of Vocal Music and the Sibelius Academy Innovation Centre: http://www2. siba.fi/vaccaj/index en.html (consultado el 17 de mayo de 2012).

\section{DISCOGRAFÍA}

KATSARIS, Cyprien, Latin American piano, Vol. 1, México, México, URTEX, JBCC 062, 2007.

Recibido: 10/12/2010

Aceptado: 14/05/2012 